\title{
DNA polymerase kappa protects human cells against MMC-induced genotoxicity through error-free translesion DNA synthesis
}

Yuki Kanemaru ${ }^{1,2^{*}}$ (D) Tetsuya Suzuki ${ }^{1,5}$, Akira Sassa $^{1}$, Kyomu Matsumoto $^{3}$, Noritaka Adachi ${ }^{4}$, Masamitsu Honma ${ }^{1}$, Satoshi Numazawa ${ }^{2}$ and Takehiko Nohmi ${ }^{1,6}$

\begin{abstract}
Background: Interactions between genes and environment are critical factors for causing cancer in humans. The genotoxicity of environmental chemicals can be enhanced via the modulation of susceptible genes in host human cells. DNA polymerase kappa (Pol $\mathrm{k}$ ) is a specialized DNA polymerase that plays an important role in DNA damage tolerance through translesion DNA synthesis. To better understand the protective roles of Pol $\mathrm{k}$, we previously engineered two human cell lines either deficient in expression of Pol $\mathrm{k}(\mathrm{KO})$ or expressing catalytically dead Pol $\mathrm{k}$ (CD) in Nalm-6-MSH+ cells and examined cytotoxic sensitivity against various genotoxins. In this study, we set up several genotoxicity assays with cell lines possessing altered Pol $\mathrm{k}$ activities and investigated the protective roles of Pol $\mathrm{k}$ in terms of genotoxicity induced by mitomycin $\mathrm{C}(\mathrm{MMC})$, a therapeutic agent that induces bulky DNA adducts and crosslinks in DNA.

Results: We introduced a frameshift mutation in one allele of the thymidine kinase (TK) gene of the $K O, C D$, and wild-type Pol $\mathrm{k}$ cells (WT), thereby establishing cell lines for the TK gene mutation assay, namely TK+/- cells. In addition, we formulated experimental conditions to conduct chromosome aberration (CA) and sister chromatid exchange (SCE) assays with cells. By using the WT TK+/- and KO TK+/- cells, we assayed genotoxicity of MMC. In the TK gene mutation assay, the cytotoxic and mutagenic sensitivities of KO TK+/- cells were higher than those of WT TK+/- cells. MMC induced loss of heterozygosity (LOH), base pair substitutions at CpG sites and tandem mutations at GpG sites in both cell lines. However, the frequencies of $\mathrm{LOH}$ and base substitutions at $\mathrm{CpG}$ sites were significantly higher in $\mathrm{KO} \mathrm{TK}+/$ cells than in WT TK+/- cells. MMC also induced CA and SCE in both cell lines. The KO TK+/- cells displayed higher sensitivity than that displayed by WT TK+/- cells in the SCE assay.
\end{abstract}

Conclusions: These results suggest that Pol $\mathrm{k}$ is a modulating factor for the genotoxicity of MMC and also that the established cell lines are useful for evaluating the genotoxicity of chemicals from multiple endpoints in different genetic backgrounds of Pol $\mathrm{K}$.

Keywords: Translesion DNA synthesis, DNA polymerase k, Nalm-6-MSH+, Genotoxicity assay, Mitomycin C

\footnotetext{
* Correspondence: yuki.0310.teto@gmail.com

${ }^{1}$ Division of Genetics and Mutagenesis, National Institute of Health Sciences,

1-18-1 Kamiyoga, Setagaya-ku, Tokyo 158-8501, Japan

${ }^{2}$ Division of Toxicology, Department of Pharmacology, Toxicology and

Therapeutics, Showa University School of Pharmacy, 1-5-8 Hatanodai,

Shinagawa-ku, Tokyo 142-0064, Japan

Full list of author information is available at the end of the article
} 


\section{Background}

Translesion DNA synthesis (TLS) is one of the strategies to circumvent persisting DNA lesions that can lead to fork collapse and cell death. TLS is performed by specialized DNA polymerases (Pols). These Pols take over primer DNA from replicative Pols, e.g., Pol $\delta$ and Pol $\varepsilon$, at or before lesions and insert dNMPs opposite lesions in an error-free or error-prone manner [1-3]. After successful lesion bypass, the replicative Pols return to the primer DNA and continue whole chromosome replication [4]. The bypass process does not accomplish repair or excision of the DNA lesions. In addition, the fidelity of TLS Pols in lesion bypass depends on the polymerases used and the type of lesions encountered. Therefore, TLS is regarded as a mode of DNA damage tolerance that may cause mutations in compensation for cell survival [5].

To date, more than ten such specialized Pols involved in TLS have been identified. Among them, the Y-family Pols $\eta, \mathrm{l}, \mathrm{K}$ and REV1, and the B-family Pol $\zeta$ have been intensively characterized $[6,7]$. Among the Y-family Pols, Pol $\mathrm{K}$ is primarily characterized by its ability to perform error-free TLS across bulky DNA adducts at $N^{2}$ position of guanine induced by benzo[a]pyrene-7,8-dihydrodiol9,10-epoxide (BPDE) [8-11]. Several in vitro studies, mostly biochemical, have also demonstrated that Pol $\mathrm{K}$ bypasses a wide variety of DNA lesions that are structurally unrelated, such as 7,8-dihydro-8-oxo-guanine [1215], thymine glycol [16, 17], $N^{3}$-methyl-adenine [18] and DNA inter-strand crosslinks [19-21]. In vivo, Pol Kdeficient mice exhibited a spontaneous mutator phenotype [22]. Besides, upregulation of Pol $\kappa$ was observed in tumor tissues from patients with non-small cell lung cancer [23], and overexpression of human Pol $\mathrm{K}$ also confers genomic instability at the cellular level [24]. These findings implicate that Pol $\kappa$ plays a role in maintaining human genome integrity.

To better understand the protective roles of Pol $\mathrm{k}$ at the cellular level, we previously generated human Pol $\mathrm{K}$ knockout (KO) [25] and catalytically dead (CD) mutants in the human Nalm-6-MSH+ cell line and examined cytotoxic sensitivity to various genotoxins [26]. We conducted the study with not only $\mathrm{KO}$ cells but also CD cells because Pol $\kappa$ interacts with other proteins, such as REV1 and proliferating cell nuclear antigen PCNA. REV1 acts as a docking site for other TLS Pols and facilitating polymerase exchange [27], and PCNA interacts with various proteins involved in DNA replication and repair pathways [28]. Therefore, a simple $\mathrm{KO}$ of Pol $\kappa$ might modulate functions of other proteins, thereby obscuring the possible catalytic protective role against genotoxic stresses. Results suggested that Pol $\kappa$ protects cells against BPDE, mitomycin $\mathrm{C}(\mathrm{MMC})$, and bleomycin via its DNA polymerase activity. In addition, we shed light on a novel non-catalytic protective role of this protein against oxidative stress induced by hydrogen peroxide. These findings have emphasized the significance of Pol $\mathrm{K}$ in the protection of human cells against various genotoxic stresses. However, whether the protective roles of Pol $\mathrm{K}$ are attributed to error-free or error-prone TLS have yet to be clarified. Therefore, in this study, we established cell lines for the thymidine kinase (TK) gene mutation assay by introducing a frameshift mutation in one allele of the TK1 in cells with altered Pol $\mathrm{k}$ activity, resulting in $\mathrm{TK}+/$ - cells. In addition, to gain insight into chromosomal events, we formulated experimental conditions for chromosome aberration (CA) and sister chromatid exchange (SCE) assays.

To evaluate the utility of the cell lines to investigate protective roles of Pol $\mathrm{\kappa}$ in terms of genotoxicity, we exposed Pol $\kappa$ wild-type (WT) $\mathrm{TK}+/$ - and $\mathrm{KO} \mathrm{TK}+/$ - cells to $\mathrm{MMC}$ and investigated gene mutations and chromosomal damage. MMC is a chemotherapeutic agent that induces monofunctional adducts, and intra- and interstrand DNA crosslinks at the $N^{2}$ position of guanine [29, 30]. Although the amounts of DNA inter-strand crosslinks are lower than those of intra-strand crosslinks or monofunctional adducts, these inter-strand crosslinks are largely responsible for the cytotoxicity of MMC [31]. Earlier studies reported that Pol $\mathrm{K}$ is involved in errorfree TLS across $N^{2}$-guanine inter-strand crosslinks and $N^{2}$-guanine monofunctional adducts [19, 32, 33]. However, the roles Pol $\mathrm{k}$ plays to protect cells from mutagenic and clastogenic effects of multiple DNA damages induced by MMC in human cells are unclear. Therefore, we analyzed the genotoxicity of MMC in human cells with different Pol $\mathrm{k}$ expression profiles by using a series of genotoxicity assays.

\section{Methods}

\section{Cell lines and culture}

The human pre-B cell line Nalm-6-MSH+ (WT) and its Pol $\mathrm{\kappa}$ derivatives, $\mathrm{KO}$ and $\mathrm{CD}$ cells, were established in our laboratory as described previously [25, 26, 34]. The KO cells were generated by deleting exon 6 of the POLK, resulting in a frameshift. The $\mathrm{CD}$ cells were also generated by introducing mutations directing amino acid substitutions in exon 6 of the POLK, D198A and E199A, which are critical to the catalytic activity of Pol $\kappa$. The cells were cultured in RPMI1640 (Nacalai Tesque, Kyoto, Japan) medium supplemented with $10 \%$ calf serum (Thermo Fisher Scientific, Waltham, MA, USA), $50 \mu \mathrm{g} / \mathrm{mL}$ kanamycin and $50 \mu \mathrm{M} 2$-mercaptoethanol in a $5 \% \mathrm{CO}_{2}$ incubator at $37{ }^{\circ} \mathrm{C}$.

\section{Chemicals}

BPDE was purchased from MRI Global (Kansas City, MO, USA) and used to evaluate the TK gene mutation assay in the $\mathrm{TK}+/$ - cells established in this study because it is known that Pol $\kappa$ can bypass BPDE-DNA adducts in 
an error-free manner [11]. MMC was purchased from Nacalai Tesque (Kyoto, Japan) and used as a test chemical because the chemotherapeutic agent induces not only bulky DNA adducts but also inter- and intra-DNA crosslinks [29,30] which are not well-known the contribution of Pol $\mathrm{K}$ in their repair processes. Dimethyl sulfoxide (DMSO) was obtained from Wako (Osaka, Japan) and used as a solvent control.

\section{Establishment of $\mathrm{TK}^{+/-}$mutant cells}

The gene-targeting vector for introducing a +1-bp frameshift mutation in exon 4 of the TK1 was constructed using MultiSite Gateway Three-Fragment Vector Construction Kit (Thermo Fisher Scientific, Waltham, MA, USA) as previously described [35]. The targeting vector was linearized by PmeI and transfected into $2 \times 10^{6} \mathrm{WT}, \mathrm{KO}$ and $\mathrm{CD}$ cells using Nucleofector ${ }^{\mathrm{Tm}} \mathrm{I}$ with Kit $\mathrm{T}$ solution (LONZA, Basel, Switzerland) according to the manufacturer's instructions. After $48 \mathrm{~h}$ of incubation, the cells were transferred into a selection medium containing 0.5 $\mu \mathrm{g} / \mathrm{mL}$ puromycin (Wako, Osaka, Japan) at a density of 2,000 cells per well in 96-well plates and cultured for twothree weeks. The resulting drug-resistant clones were subjected to PCR analysis with primers TK ex4 TG Fw and $5^{\prime}$-loxP TG to screen the targeted integrant at exon 4 of the TK1. Subsequently, the targeted +1-bp frameshift mutation induction was verified by DNA sequencing using primers TK ex4 Fw and TK ex4 Rv. For the successfully targeted integrants, the drug resistance gene was excised by transient expression of Cre recombinase via electroporation of the Cre expression vector. Excision of the drug resistance gene was confirmed by PCR with primers TK ex4 TG Fw and PGK pro. All PCR reactions were performed using KOD FX (TOYOBO, Osaka, Japan). The primer sequences used for the PCR and DNA sequencing are listed in (Additional file 1: Table S1).

\section{TK gene mutation assay}

Established cell lines harboring the $T K^{+/-}$mutation were cleansed with CHAT (C: $20 \mu \mathrm{M}$ 2'-deoxycytidine, H: 200 $\mu \mathrm{M}$ hypoxanthine, A: $0.1 \mu \mathrm{M}$ aminopterin, T: $17.5 \mu \mathrm{M}$ thymidine (Sigma-Aldrich, St. Louis, MO, USA)) solution prior to use as described previously [36]. Five milliliters of cell suspensions $\left(5 \times 10^{5}\right.$ cells $\left./ \mathrm{mL}\right)$ were treated with $6.25,12.5$ and $25 \mathrm{nM}$ of BPDE or 50,100 and $200 \mathrm{ng} / \mathrm{mL}$ of MMC for $3 \mathrm{~h}$ at $37^{\circ} \mathrm{C}$. After treatment, the cells were centrifuged, washed once, and then re-suspended in a fresh medium at a density of $2 \times 10^{5}$ cells $/ \mathrm{mL}$. We also seeded the cells into 96-well plates ( 2.5 cells/well) concurrently for determining plating efficiency (PE0). After a 96-h expression period, the cell suspension was seeded in 96-well plates at $2.5 \times 10^{4}$ cells/well in the presence of $3 \mu \mathrm{g} / \mathrm{mL}$ trifluorothymidine (TFT) to isolate $T K^{-1-}$ mutants. We also seeded the cells into 96-well plates ( 2.5 cells/well) in the absence of TFT for plating efficiency determination (PE4). All 96-well plates were incubated for more than 20 days at $37^{\circ} \mathrm{C}$, and then the number of wells with colonies in PE0 and PE4 plates and $T_{K^{-1}}$ mutant colonies in TFT plates were scored. $\mathrm{Mu}$ tant frequencies and relative cell survivals were calculated using previously described method [37]. Comparisons of mutant frequencies or relative cell survivals between cell lines were quantified using Student's $t$-test. The level of statistical significance was set at $P<0.05$.

\section{Mutation spectrum analysis of $\mathrm{TK}^{-1-}$ mutants}

Cleansed cells treated with $200 \mathrm{ng} / \mathrm{mL}$ MMC or DMSO as described in 2.4 were washed once and immediately seeded in 96-well plates $\left(1 \times 10^{5}\right.$ cells/well for cells treated with MMC and $1.25 \times 10^{5}$ cells/well for solvent control, respectively) to obtain independent $T K^{-1} \mathrm{mu}-$ tant clones. After a $96 \mathrm{~h}$ culture for expression period, TFT was added to each well of the plates at a final concentration of $3 \mu \mathrm{g} / \mathrm{mL}$, and the cells were incubated for more than 20 days at $37^{\circ} \mathrm{C}$. The resulting TFT-resistant clones were subjected to genomic PCR to amplify exon 4 of the TK1 using primers TK ex4 Fw and TK ex4 Rv2 to classify the mutants as $\mathrm{LOH}$ type, $T K^{-1-}$ mutants harboring large deletion or inter-allelic homologous recombination (one band), or non- $\mathrm{LOH}$, i.e., $T K^{-1-}$ mutants harboring intragenic mutations (two bands). The PCR products of the non-functional (gene-targeted) TK1 allele were approximately $100 \mathrm{bp}$ longer than those of the functional allele due to residual sequence of the targeting vector around the loxP site. For non- $\mathrm{LOH}$ mutants, total RNA was extracted using ISOGEN II (Nippon Gene, Tokyo, Japan) and then amplified with PrimeScript OneStep RT-PCR Kit ver. 2 (TaKaRa, Shiga, Japan) using the primers TK c176 Fw and TK c983 Rv. Resulting cDNA sequences were analyzed with 3130 Avant Genetic Analyzer (Thermo Fisher Scientific, Waltham, MA, USA) using primers TK cDNA seq Fw1 and TK cDNA seq Fw2. In the case of RNA splicing mutants, to analyze mutations around the splicing donor or acceptor sequences, genomic DNA was also extracted using Gentra Puregene Cell Kit (QIAGEN, Hilden, Germany), and the TK locus was amplified by PCR using sets TK95 Fw and TK4795 Rv for exons 1-4 and TK11175 Fw and TK12940 Rv for exon 5 to 7. The amplified genomic DNA sequences were analyzed using primers TK c176 Fw for exons 1-2, gTK ex3 seq Fw for exon 3,TK ex4 Fw for exon 4, gTK ex5\&6 seq Fw for exon 5, and TK c983 Rv for exon 6-7.

\section{Chromosome aberration assay}

Five milliliter of cell suspension $\left(2.5 \times 10^{5}\right.$ cells $\left./ \mathrm{mL}\right)$ was treated with 50 and $100 \mathrm{ng} / \mathrm{mL} \mathrm{MMC}$ for $3 \mathrm{~h}$ at $37{ }^{\circ} \mathrm{C}$. The highest concentration was set to achieve reduction in RICC to $45 \pm 5 \%$ of the concurrent solvent control 
for both cell lines in accordance with the OECD Guideline for the Testing of Chemicals TG 473. The cells were washed once and cultured in fresh medium for $24 \mathrm{~h}$. Two hours prior to harvesting cells, colcemid (SERVA Electrophoresis, Heidelberg, Germany) was added to the medium at a final concentration of $0.2 \mu \mathrm{g} / \mathrm{mL}$. For chromosomal preparation, cells were swollen with 0.075 $\mathrm{M}$ potassium chloride for $10 \mathrm{~min}$ at room temperature, fixed with a solution of methanol : acetic acid $=3: 1$, and then air-dried on glass slides. All slides were coded and stained with $2 \%(\mathrm{v} / \mathrm{v})$ Giemsa solution (Merck, Darmstadt, Germany) for $15 \mathrm{~min}$ at room temperature. Two hundreds of well-spread metaphase cells per dose were scored for chromosomal aberrations including breaks, exchanges and gaps at $\times 1000$ magnification. The differences in the number of cells with chromosome aberrations between WT and KO cells were analyzed statistically using a chi-square test. The level of statistical significance was set at $P<0.05$.

\section{Sister chromatid exchange assay}

Cells treated with MMC for $3 \mathrm{~h}$ as described in 2.6 were washed once and cultured in a fresh medium containing $2 \mu \mathrm{g} / \mathrm{mL}$ of 5-bromo-2'-deoxyuridine (Sigma-Aldrich, St. Louis, MO, USA) for $48 \mathrm{~h}$. Colcemid treatment and chromosomal preparation were performed as described in 2.5. The slides were coded and stained with $3 \%(\mathrm{v} / \mathrm{v})$ Giemsa solution containing 2\% (w/v) EDTA 4Na for 5 min at $40{ }^{\circ} \mathrm{C}$ [38]. Fifty well-spread metaphase cells containing 42-46 chromosomes were examined for SCE. The average number of SCEs per cell was calculated and statistically compared between WT TK+/- and KO TK $+/$ - cells at the same dose concentrations using Student's $t$-test. The level of statistical significance was set at $P<$ 0.05 .

\section{Results}

Establishment of TK gene mutation assay in Nalm-6-MSH + cells and Their Pol $\mathrm{K}$ derivatives

To establish the TK gene mutation assay, a +1 -bp frameshift mutation was introduced at exon 4 of one allele of the TK1 in WT, KO and CD cells (Fig. 1a). The targeted heterozygous frameshift mutation, CCC to CCCC, was verified by DNA sequencing (Fig. 1b). The resulting cell lines were named as WT TK+/-, KO TK+/-, and CD TK+/- based on the different expression profile of Pol $\kappa$. Those three cell lines had comparable doubling times (WT TK+/-: $21.5 \pm$ $0.6 \mathrm{~h}, \mathrm{KO} \mathrm{TK}+/-: 20.9 \pm 0.6 \mathrm{~h}$, and CD TK+/-: $22.2 \pm 0.8$ $\mathrm{h})$, which were not significantly different from the original WT, KO, and CD cells, respectively [26]. The spontaneous $T K$ mutant frequency of $\mathrm{KO} \mathrm{TK}+/$ - cells was higher than those of WT TK+/- and CD TK+/- cells, but this difference was not statistically significant (Table 1 ). In addition to the gene mutation assay, we also determined the baseline frequencies of CA and SCE in established cell lines. The incidences of spontaneous $\mathrm{CA}$ in $\mathrm{KO} \mathrm{TK}+/-$ and $\mathrm{CD} \mathrm{TK}+/$ cells were comparable to those in WT $\mathrm{TK}+/$ - cells, whereas $\mathrm{KO} \mathrm{TK}+/$ - cells exhibited a significantly higher incidence of spontaneous SCE than WT TK+/- cells (Table 1).

Additionally, we determined the $T K$ mutant frequencies of WT $\mathrm{TK}+/$ - and $\mathrm{KO} \mathrm{TK}+/$ - cells treated with BPDE. As a result of cytotoxicity, $\mathrm{KO} \mathrm{TK}+/$ - cells exhibited hypersensitivity to BPDE compared to WT $\mathrm{TK}+/$ cells (Fig. 1c). Both cell lines exhibited concentrationrelated increases in the $T K$ mutant frequency, and $\mathrm{KO}$ $\mathrm{TK}+/$ - cells displayed a significantly higher mutant frequency than WT TK+/- cells (Fig. 1d). The enhanced mutagenicity of BPDE in Pol $k$-deficient cells is consistent with previous studies using the Hprt gene mutation assay in mouse ES cells [8] and the supF forward mutation assay in the parental Nalm-6 human Pre-B cell line [25]. Therefore, we judged the $T K$ gene mutation assay in the established cell lines to be functional for analyzing the genotoxicity of test articles.

\section{Cytotoxic and genotoxic responses to MMC}

We treated $\mathrm{KO} \mathrm{TK}+/$ - and WT $\mathrm{TK}+/$ - cells with MMC and examined cytotoxicity and genotoxicity via the $T K$ gene mutation assay. In cell survival analysis, $\mathrm{KO} \mathrm{TK}+/$ cells exhibited hypersensitivity to the cytotoxic effect of MMC compared to WT TK+/- cells (Fig. 2a). The TK mutant frequencies of $\mathrm{KO} \mathrm{TK}+/$ - cells were significantly higher than those of WT $\mathrm{TK}+/$ - cells at the concentrations of 100 and $200 \mathrm{ng} / \mathrm{mL}$ (Fig. 2b). These results suggest that the expression of wild-type Pol $\kappa$ facilitates cell survival against MMC via error-free TLS.

\section{Mutation spectrum analysis}

To address the sequence specificity of MMC-induced DNA lesions bypassed by Pol $\kappa$, we analyzed the mutation spectra of the spontaneous and MMC-induced TK ${ }^{-/}$mutants (Table 2). A summary of all mutations is shown in (Additional file 1: Table S2). The frequencies of $\mathrm{G}: \mathrm{C}$ to $\mathrm{C}: \mathrm{G}$ transversions and tandem base substitutions at $\mathrm{GpG}$ sites were substantially increased by MMC treatment in both cell lines. The proportion of $\mathrm{LOH}$ mutants among $\mathrm{KO} \mathrm{TK}+/$ - cells was also increased by MMC treatment.

To compare the mutation spectra of MMC-induced DNA lesions in WT TK+/- and $\mathrm{KO} T K+/$ - cells, the absolute contribution of mutations at $\mathrm{CpG}$ or $\mathrm{GpG}$ sites and $\mathrm{LOH}$ was calculated by multiplying the $T K$ mutant frequency at an MMC concentration of $200 \mathrm{ng} / \mathrm{mL}$ by the proportion of each type of mutations listed in Table 2 (Fig. 3). In the solvent control group, most of the $T K^{-1-}$ mutants displayed $\mathrm{LOH}$ and point mutations at bases other than CpG or GpG, and the ratio between $\mathrm{LOH}$ and point mutations was comparable between cell lines 


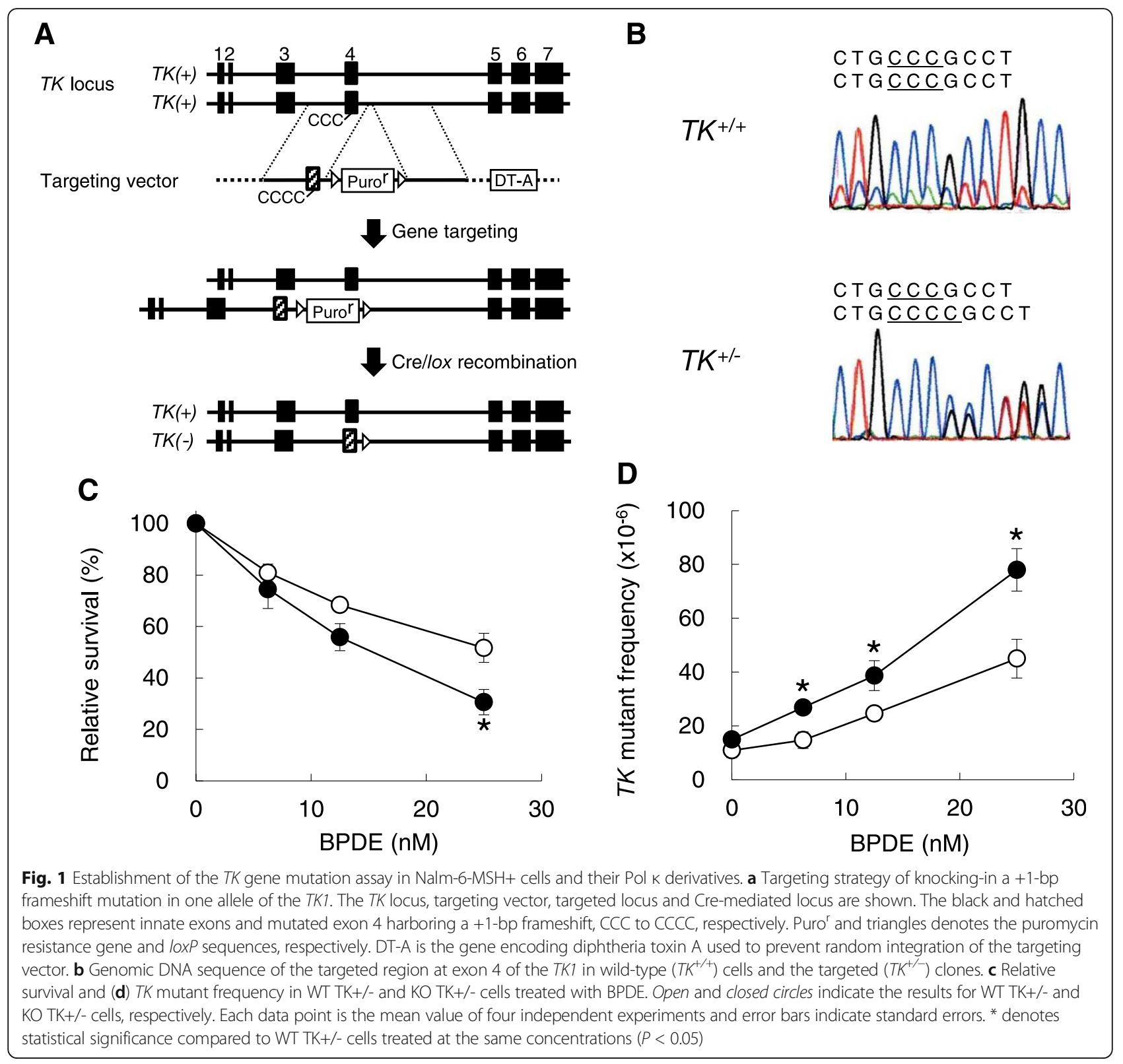

Table 1 Baseline frequencies of the $\mathrm{TK}^{-/}$mutation, CA and SCE in Nalm-6-MSH+ TK+/- cells and their Pol $k$ derivatives

\begin{tabular}{llll}
\hline & TK mutant frequency $^{\mathrm{a}}$ & $\mathrm{CA}^{\mathrm{b}}$ & $\mathrm{SCE}^{\mathrm{C}}$ \\
\hline & $\left(\times 10^{-6}\right)$ & $(\%)$ & (incidence/cell) \\
WT TK+/- & $7.8 \pm 2.4$ & 1.5 & $4.5 \pm 2.2$ \\
KO TK+/- & $14.1 \pm 2.9$ & 2.0 & $6.9 \pm 2.9^{*}$ \\
CD TK+/- & $9.9 \pm 3.2$ & 1.0 & $4.9 \pm 1.8$ \\
\hline
\end{tabular}

aalues are the mean \pm S.E. $(n=3)$

${ }^{\mathrm{b}}$ Two hundred metaphase cells were analyzed for each cell type $(n=1)$

${ }^{C}$ Fifty metaphase cells were analyzed. Data are expressed as the mean \pm S.D.

$(n=1) .{ }^{*}$ denotes a significant difference compared to WT TK+/- cells
(Fig. 3a). In the MMC treatment group, however, the frequency of MMC-induced base substitution at $\mathrm{CpG}$ sites was increased 3.1 times in $\mathrm{KO} \mathrm{TK}+/$ - cells compared to WT TK+/- cells (WT TK+/-: $5.4 \times 10^{-6}$ versus KO TK $\left.+/-: 16.7 \times 10^{-6}\right)$ (Fig. 3b). In addition, the frequency of $\mathrm{LOH}$ mutation in $\mathrm{KO} \mathrm{TK}+/$ - cells treated with $\mathrm{MMC}$ was 3.4 times higher than that in WT TK+/- cells (WT $\mathrm{TK}+/$-: $13.8 \times 10^{-6}$ versus $\mathrm{KO} \mathrm{TK}+/$-: $\left.46.4 \times 10^{-6}\right)$. In contrast, the frequencies of the MMC-induced tandem base pair substitutions at $\mathrm{GpG}$ sites were comparable between the cell lines (WT TK+/-: $4.2 \times 10^{-6}$ versus $\mathrm{KO}$ $\mathrm{TK}+$ /-: $\left.4.8 \times 10^{-6}\right)$. Other base pair substitutions and frameshift mutation frequencies were not substantially increased by MMC treatment. 

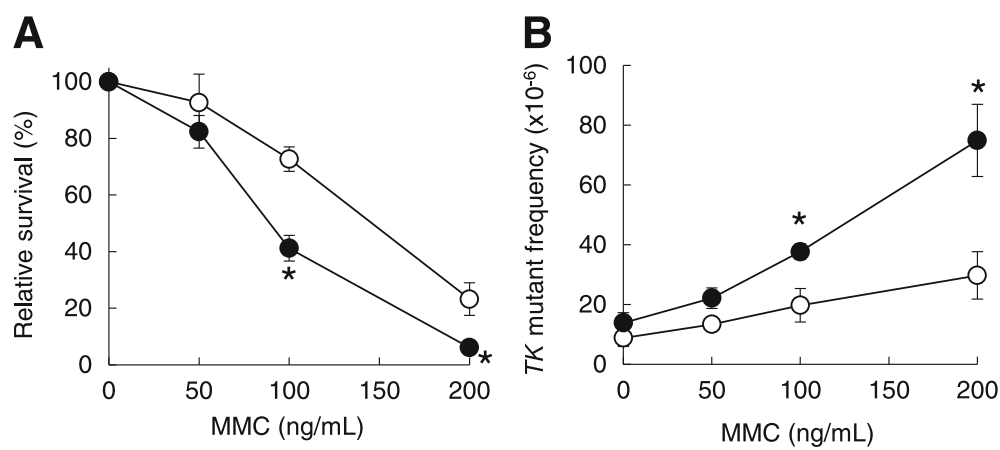

Fig. 2 Cytotoxicity and TK mutant frequency in WT TK+/- and KO TK+/- cells treated with MMC. a Relative survival and (b) TK mutant frequency. Open and closed circles indicate the results in WT TK+/- and KO TK+/- cells, respectively. Each data point is the mean value of four independent experiments, and error bars indicate standard error. ${ }^{*}$ denotes the statistical significance compared to WT TK+/- cells treated the same concentration $(P<0.05)$

\section{Chromosome analysis}

We measured the structural abnormalities of chromosomes for further investigation of $\mathrm{LOH}$ events after MMC treatment. Figure $4 \mathrm{a}$ and $\mathrm{b}$ show the results of $\mathrm{CA}$ and SCE assays, respectively. The incidences of both CA and $\mathrm{SCE}$ were elevated by MMC treatment in a concentrationdependent manner, and the frequencies of $\mathrm{CA}$ were

Table 2 Summary of the mutation spectra of $\mathrm{TK}^{-1-}$ mutantations $^{a}$

\begin{tabular}{|c|c|c|c|c|}
\hline & \multicolumn{2}{|c|}{ Solvent control } & \multicolumn{2}{|l|}{ MMC } \\
\hline & $\overline{\text { WT TK+/- }}$ & $\overline{\mathrm{KO} T K+/-}$ & $\overline{\text { WT TK+/- }}$ & $\mathrm{KO}$ TK +/- \\
\hline \multicolumn{5}{|l|}{ Base substitution } \\
\hline \multicolumn{5}{|l|}{ Transition } \\
\hline $\mathrm{A}: \mathrm{T} \rightarrow \mathrm{G}: \mathrm{C}$ & $10(36)$ & $11(26)$ & $6(6)$ & $5(4)$ \\
\hline $\mathrm{G}: \mathrm{C} \rightarrow \mathrm{A}: \mathrm{T}$ & $1(4)$ & $2(5)$ & $5(5)$ & $4(3)$ \\
\hline \multicolumn{5}{|l|}{ Transversion } \\
\hline $\mathrm{A}: \mathrm{T} \rightarrow \mathrm{T}: \mathrm{A}$ & $0(0)$ & $2(5)$ & $1(1)$ & $0(0)$ \\
\hline $\mathrm{A}: \mathrm{T} \rightarrow \mathrm{C}: \mathrm{G}$ & $0(0)$ & $2(5)$ & $4(4)$ & $1(1)$ \\
\hline $\mathrm{G}: \mathrm{C} \rightarrow \mathrm{T}: \mathrm{A}$ & $3(11)$ & $10(23)$ & $10(11)$ & $17(13)$ \\
\hline $\mathrm{G}: \mathrm{C} \rightarrow \mathrm{C}: \mathrm{G}$ & $0(0)$ & $1(2)$ & $8(9)$ & $9(7)$ \\
\hline \multicolumn{5}{|l|}{ Tandem } \\
\hline $\mathrm{GG}: \mathrm{CC} \rightarrow \mathrm{CT}: \mathrm{GA}$ & $0(0)$ & $0(0)$ & $3(3)$ & $2(2)$ \\
\hline $\mathrm{GG}: \mathrm{CC} \rightarrow \Pi \mathrm{T}: \mathrm{AA}$ & $0(0)$ & $0(0)$ & $8(9)$ & $6(5)$ \\
\hline $\mathrm{GG}: \mathrm{CC} \rightarrow \mathrm{AT}: \mathrm{TA}$ & $0(0)$ & $0(0)$ & $2(2)$ & $0(0)$ \\
\hline $\mathrm{CA}: \mathrm{GT} \rightarrow \mathrm{TG}: \mathrm{AC}$ & $1(4)$ & $0(0)$ & $0(0)$ & $0(0)$ \\
\hline $\mathrm{AG}: \mathrm{TC} \rightarrow \mathrm{CT}: \mathrm{GA}$ & $0(0)$ & $0(0)$ & $0(0)$ & $1(1)$ \\
\hline Frameshift $(+1)$ & $0(0)$ & $0(0)$ & $1(1)$ & $1(1)$ \\
\hline Frameshift $(+2)$ & $1(4)$ & $0(0)$ & $0(0)$ & $0(0)$ \\
\hline Frameshift $(-1)$ & $0(0)$ & $0(0)$ & $0(0)$ & $2(2)$ \\
\hline $\mathrm{LOH}$ & $12(43)$ & $15(35)$ & $43(46)$ & $78(62)$ \\
\hline Unidentified & $0(0)$ & $0(0)$ & $2(2)$ & $0(0)$ \\
\hline Total & $28(100)$ & $43(100)$ & $93(100)$ & $126(100)$ \\
\hline
\end{tabular}

${ }^{a}$ Data are presented as number of clones (ratio), with the results of two independent experiments are aggregated comparable between WT $\mathrm{TK}+/$ - and $\mathrm{KO} \mathrm{TK}+/$ - cells. Conversely, the incidence of SCE in $\mathrm{KO} \mathrm{TK}+/$ - cells was significantly higher than that in WT $\mathrm{TK}+/-$ cells. SCE is known as a cytological manifestation of homologous recombination. Thus, results suggest that the increase in $\mathrm{LOH}$ events in $\mathrm{KO} \mathrm{TK}+/$ - cells might be attributed to the induction of DNA strand breaks and the subsequent homologous recombination repair pathway.

\section{Discussion}

In this study, to provide insights into the protective roles of Pol $\mathrm{K}$ against genotoxic stresses, we have established $\mathrm{WT} \mathrm{TK}+/-$, $\mathrm{KO} \mathrm{TK}+/$ - and $\mathrm{CD} \mathrm{TK}+/$ - cells for conducting the $T K$ gene mutation assay. The TK gene mutation assay is widely used in in vitro genotoxicity studies because it can detect both gene mutations and chromosomal events such as large deletions, chromosome rearrangements and mitotic recombination [39]. In terms of point mutations, mutation spectrum analysis of TK-deficient mutants allows us to obtain detailed information of the sequence specificity of these events. In addition, to gain insight into chromosomal damage, we have also formulated experimental conditions for the CA assay for structural damage and the SCE assay for mitotic recombination in response to DNA damage.

As previously described, the Nalm-6-MSH+ cell line which is the background cell line of $\mathrm{KO} \mathrm{TK}+/-, \mathrm{CD} \mathrm{TK}+/-$, and WT $\mathrm{TK}+/$ - cells in this study, was engineered by restoring MSH2 expression in human Nalm-6 cells which possess an exceptionally high gene-targeting efficiency, resulting in proficient mismatch repair function as well as low spontaneous mutant frequency [34]. The $T K$ gene mutation assay in the WT TK+/- cells also indicated a low spontaneous $T K$ mutant frequency $\left(7.8 \times 10^{-6}\right)$, and this value is comparable to that seen in human lymphoblastoid TK6 cells [36]. In addition, the original Nalm- 6 cell line, a parental cell line of Nalm-6-MSH+, has a normal p53 status and near diploid karyotype [40]. These properties, 

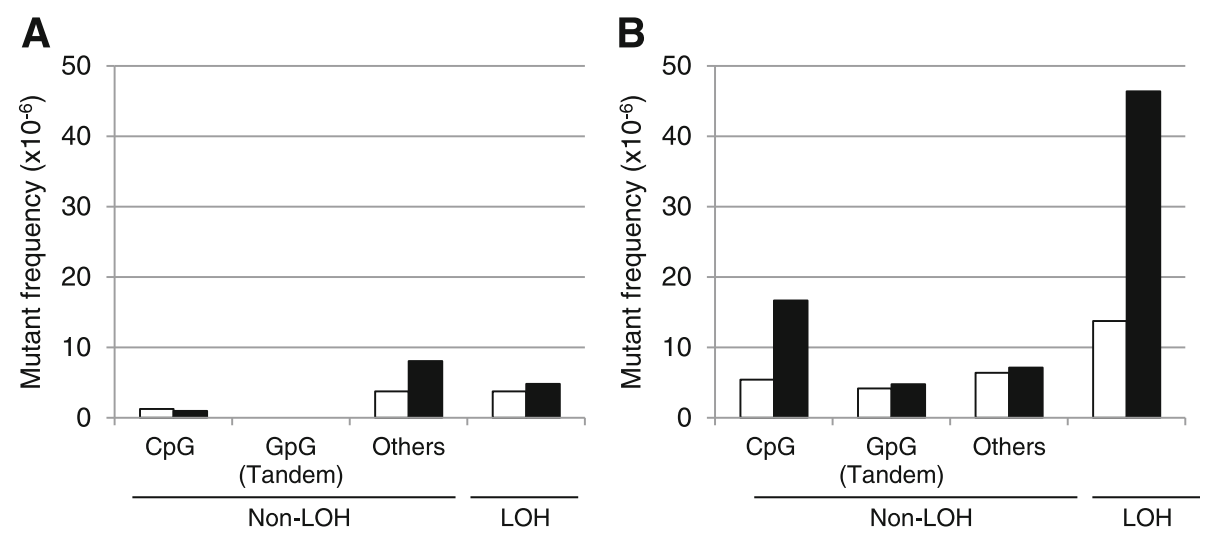

Fig. 3 Types of mutations that contributed to TK mutant frequencies induced by MMC treatment. a Solvent control and (b) MMC. The TK mutant frequencies for each type of mutation were calculated by multiplying the mean of mutant frequency at $0 \mathrm{ng} / \mathrm{mL}$ (solvent control) and $200 \mathrm{ng} /$ $\mathrm{mL} M M C$ taken from Fig. $2 \mathrm{~b}$ by the ratio of each type of mutation described in Table 2. For non-LOH mutants, single base pair substitutions and frameshifts at $\mathrm{CpG}$ sites, tandem base pair substitutions at $\mathrm{GpG}$ sites, and all the other point mutations are shown separately. White and black boxes indicate the results for WT TK+/- and KO TK+/- cells, respectively

combined with high gene-targeting efficiency, emphasize the usefulness of this cell line as a system to investigate the functions of specific protein(s) in the protection of human genome integrity against genotoxic stresses.

Using the WT $\mathrm{TK}+/$ - and $\mathrm{KO} \mathrm{TK}+/$ - cells, we addressed the protective role of Pol $\mathrm{K}$ against MMC genotoxicity. We did not utilize CD $\mathrm{TK}+/$ - cells, as $\mathrm{KO}$ and CD cells exhibited similar sensitivity to MMC treatment in our previous study [26]. Results from the $T K$ gene mutation assay revealed a higher mutant frequency after MMC treatment in $\mathrm{KO} \mathrm{TK}+/$ - cells than in WT $\mathrm{TK}+/$ cells (Fig. 2b). Interestingly, there was a close relationship between the dose-related increase in the mutant frequency and cytotoxicity in both cell lines (Fig. 2). The relationship was also observed in BPDE treatment (Fig. 1c and d). The results of the mutant frequency and the survival suggest that both MMC- and BPDE-induced DNA lesions are bypassed by Pol $\mathrm{k}$ in an error-free manner, which plays an important protective role against cell death induced by these chemicals (see the discussion below and Fig. 5).

Mutation spectrum analysis of the $T K^{-1}$ mutants revealed that the expression of wild-type Pol $\kappa$ suppresses mutations at CpG sites but not at GpG sites or other sequences (Fig. 3b), suggesting that Pol $\mathrm{k}$ protects cells against $\mathrm{MMC}$-induced genotoxic stresses via error-free TLS across the CpG inter-strand crosslinks at guanine bases in DNA. Two major pathways of DNA interstrand crosslink repair at different cell cycle stages have been reported, replication-dependent or replicationindependent repair [41]. In the replication-dependent repair process, the Fanconi anemia pathway is activated, resulting in the ubiquitylation of FANCD2-I [42], followed by unhooking of one side of crosslinking DNA strands by several nucleases, such as ERCC1-XPF and MUS81 [43]. On the other hand, in the replicationindependent repair process, global genomic as well as transcription-coupled nucleotide excision repair (NER)
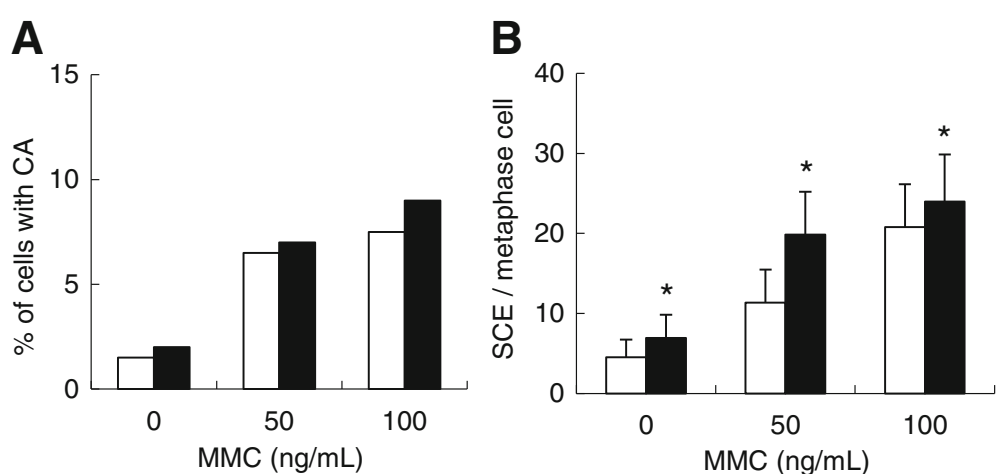

Fig. 4 CA and SCE incidences in WT TK+/- and KO TK+/- cells treated with MMC. a CA assay and (b) SCE assay. White and black boxes represent WT TK+/- and KO TK+/- cells, respectively. Both results were drawn from single experiments. Error bars indicate the standard deviation from SCEs of 50 metaphase cells, and * denotes the statistical significance between WT TK+/- and KO TK+/- cells at the same dose concentrations ( $P<0.05$ ) 


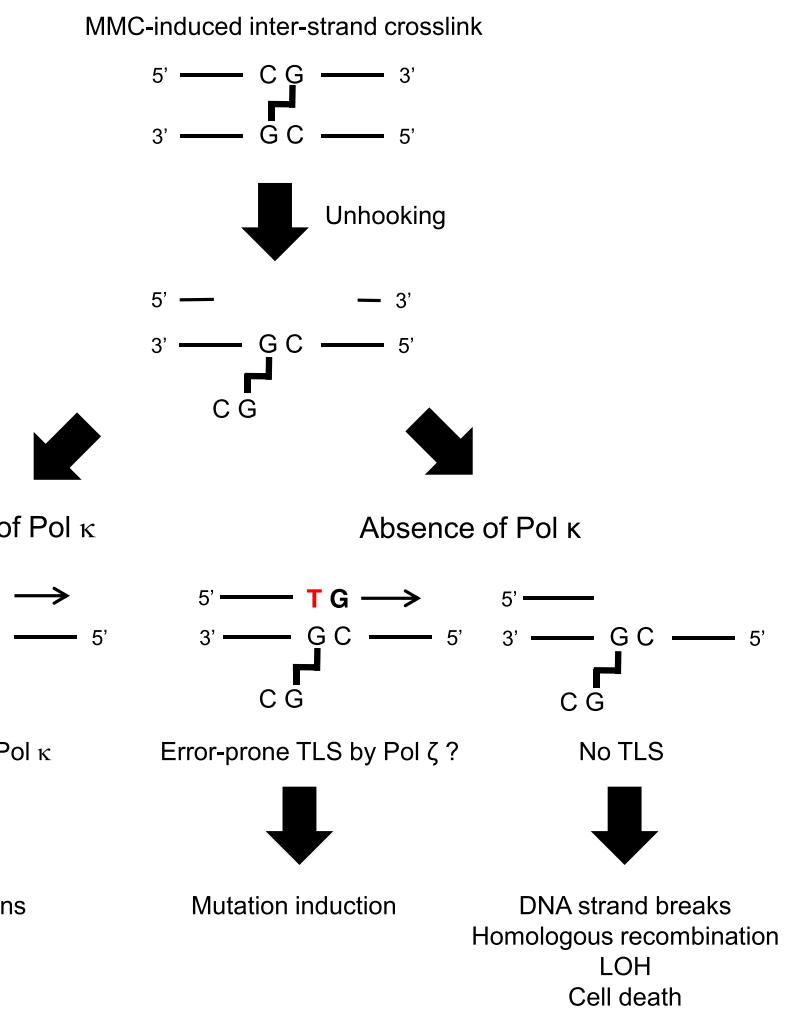

Fig. 5 A schematic of the role of Pol $\mathrm{k}$ in MMC-induced inter-strand crosslinks repair. When wild-type Pol $\mathrm{k}$ is functional, error-free TLS suppresses mutation inductions (left). When Pol $\mathrm{k}$ is deficient, other TLS Pols, such as Pol $\zeta$, bypass the lesions in an error-prone manner (middle), or replication stalling leads to chromosomal alteration or cell death (right)

pathway is known to be involved in resection of the duplex around crosslinking site $[44,45]$. In both pathways, the unhooked crosslinked strand is bypassed by TLS Pols. Pol $\mathrm{k}$ was supposed to be involved in the TLS process, but the fidelity of Pol $\mathrm{k}$-dependent DNA synthesis beyond the lesion had yet to be clarified in human cells $[19-21,46]$. The results of the present study clearly demonstrate that Pol $\kappa$ plays a substantial role in MMCinduced inter-strand crosslink repair through accurate TLS in human cells. Other TLS Pols such as Pol $\zeta$ and REV1 may also be involved in the TLS process but in an error-prone manner [46]. The involvement of Pol $\mathrm{K}$ in the TLS suppresses both mutations as well as strand breaks in DNA because the LOH mutant in the TK gene mutation assay and the SCE incidence were significantly increased in $\mathrm{KO} \mathrm{TK}+/$ - cells treated with MMC (Table 2 and Fig. 4b). In case that the MMC-induced DNA interstrand crosslinks are not bypassed by TLS polymerases, the DNA lesions might cause replication fork collapse and double strand breaks, which can lead chromosomal alterations or cell death. Taken together, we suggest that Pol $\mathrm{\kappa}$ protects cells against MMC-induced genotoxicity through error-free TLS of CpG inter-strand crosslinks, resulting in the avoidance of mutation induction by other TLS Pols or cell death (Fig. 5).
Recently, it has been reported that gpt delta mice expressing catalytically inactive Pol $\kappa$ exhibited an elevated frequency of mutations at CpG and also GpG sequences in bone marrow after MMC treatment [32]. The results presented here with $\mathrm{CpG}$ inter-strand crosslinks are consistent with the in vivo results and are also supported by biochemical evidence that Pol $\mathrm{k}$ accurately bypasses the $N^{2}-N^{2}$ inter-strand crosslinks at CpG sites [19]. In contrast, there is a discrepancy with respect to mutation induction at GpG intra-strand crosslinks between the results in mice and human cells. The reason for this discrepancy is unclear, but one possible explanation is the difference in NER activity between Nalm-6-MSH+ cells and mice. Indeed, the $N^{2}-N^{2}$ intra-strand crosslinks induced by MMC, as well as cisplatin, could be substrates for NER [47]. Pol $\kappa$ is supposed to function in a late step of NER as a gap-filling polymerase with replicate Pols [48], but this role appears to be more substantial under conditions of low nucleotide concentrations [49]. Nalm6-MSH+ cells comprise a cancer-derived cell line generally believed to exhibit proficient nucleotide pools for continuous proliferation compared to normal cells. Therefore, we speculate that the MMC-induced GpG intra-strand crosslinks cannot be substrates for NER by Pol $\mathrm{K}$ in Nalm-6-MSH+ cell lines; thus the mutation 
induction at the GpG site was similar between the WT $\mathrm{TK}+/$ - and $\mathrm{KO} \mathrm{TK}+/$ - cells in this study. In fact, $\mathrm{KO}$ cells did not exhibit hypersensitivity to UV-C light in our previous study [26] despite the discovery of hypersensitivity in mouse ES cells [8, 49].

\section{Conclusions}

In this study, we set up the cell lines for the TK gene mutation assay and also experimental condition for CA and SCE assays in a Nalm-6-MSH+ cell lines with different expression profiles of Pol $\kappa$. The cell lines can be used to evaluate the genotoxicity of chemicals from different scopes including gene mutation, chromosome aberration, and homologous recombination, in the same background. Using this cell lines, we found that Pol $\kappa$ protects human cells against MMC-mediated genotoxicity by performing error-free TLS across CpG inter-strand crosslinks. This cell line could lead to a better understanding of the roles of Pol $\mathrm{k}$ in terms of susceptibility to chemical carcinogenesis.

\section{Additional file}

Additional file 1: Table S1. Primer list. Table S2. Mutation spectra of $\mathrm{TK}^{-1-}$ mutants. (XLSX $23 \mathrm{~kb}$ )

\section{Abbreviations}

BPDE: Benzo[a]pyrene-7,8-dihydrodiol-9,10-epoxide; CA: Chromosome aberration; CD: Nalm-6-MSH+ cell expressing catalytically dead Pol K; KO: Pol K-deficient Nalm-6-MSH+ cell; LOH: Loss of heterozygosity; MMC: Mitomycin C; NER: Nucleotide excision repair; PE: Plating efficiency; Pol: DNA polymerase; SCE: Sister chromatid exchange; TFT: Trifluorothymidine; TK: Thymidine kinase; TLS: Translesion DNA synthesis; WT: Wild-type Nalm-6$\mathrm{MSH}+$ cell

\section{Acknowledgments}

This work was supported by grants-in-aid for scientific research from the Ministry of Education, Culture, Sports, Science and Technology, Japan (MEXT, 18201010; 22241016; 26281029), the Ministry of Health, Labour and Welfare, Japan (MHLW, H21-Food-General-009), the Japan Health Science Foundation (KHB1007), and the Food Safety Commission.

\section{Authors' contributions}

YK, TS and TN designed the study. TS, AS and NA designed the genetargeting procedure. YK established the TK gene mutation assay in Nalm-6$\mathrm{MSH}+$ cells and their Pol $\mathrm{K}$ derivatives. YK performed the TK gene mutation assay and mutation spectrum analysis. YK and KM performed the CA and SCE assay. TS, AS, TN, MH and SN provided intellectual input regarding the study design and interpretation of data. YK drafted the manuscript, and TN and $\mathrm{SN}$ refined the manuscript. All authors read and approved the final manuscript.

\section{Competing interest}

The authors declare that they have no competing interests.

\section{Author details}

'Division of Genetics and Mutagenesis, National Institute of Health Sciences, 1-18-1 Kamiyoga, Setagaya-ku, Tokyo 158-8501, Japan. ${ }^{2}$ Division of Toxicology, Department of Pharmacology, Toxicology and Therapeutics, Showa University School of Pharmacy, 1-5-8 Hatanodai, Shinagawa-ku, Tokyo 142-0064, Japan. ${ }^{3}$ Toxicology Division, The Institute of Environmental Toxicology, 4321 Uchimoriya-machi, Joso-shi, Ibaraki 303-0043, Japan. ${ }^{4}$ Graduate School of Nanobioscience, Yokohama City University, 22-2 Seto, Kanazawa-ku, Yokohama 236-0027, Japan. ${ }^{5}$ Present Addresses: Graduate
School of Biomedical and Health Sciences, Hiroshima University, 1-2-3 Kasumi, Minami-ku, Hiroshima 734-8553, Japan. ${ }^{6}$ Present Addresses: Biological Safety Research Center, National Institute of Health Sciences, 1-18-1 Kamiyoga, Setagaya-ku, Tokyo 158-8501, Japan.

Received: 27 July 2016 Accepted: 8 December 2016

Published online: 07 January 2017

References

1. Friedberg EC, Wagner R, Radman M. Specialized DNA polymerases, cellular survival, and the genesis of mutations. Science. 2002;296:1627-30.

2. Prakash S, Johnson RE, Prakash L. Eukaryotic translesion synthesis DNA polymerases: specificity of structure and function. Annu Rev Biochem. 2005; 74:317-53.

3. Nohmi T. Environmental stress and lesion-bypass DNA polymerases. Annu Rev Microbiol. 2006:60:231-53.

4. Friedberg EC, Lehmann AR, Fuchs RP. Trading places: how do DNA polymerases switch during translesion DNA synthesis? Mol Cell. 2005;18:499-505.

5. Sale JE, Lehmann AR, Woodgate R. Y-family DNA polymerases and their role in tolerance of cellular DNA damage. Nat Rev Mol Cell Biol. 2012;13:141-52.

6. Ohmori H, Friedberg EC, Fuchs RP, Goodman MF, Hanaoka F, Hinkle D, et al. The Y-family of DNA polymerases. Mol Cell. 2001;8:7-8.

7. Gibbs PE, McGregor WG, Maher VM, Nisson P, Lawrence CW. A human homolog of the Saccharomyces cerevisiae REV3 gene, which encodes the catalytic subunit of DNA polymerase zeta. Proc Natl Acad Sci U S A. 1998;95:6876-80.

8. Ogi T, Shinkai $Y$, Tanaka $K$, Ohmori H. Polkappa protects mammalian cells against the lethal and mutagenic effects of benzo[a]pyrene. Proc Natl Acad Sci U S A. 2002;99:15548-53.

9. Suzuki N, Ohashi E, Kolbanovskiy A, Geacintov NE, Grollman AP, Ohmori H, et al. Translesion synthesis by human DNA polymerase kappa on a DNA template containing a single stereoisomer of dG-(+)- or dG-(-)-anti-N(2)BPDE (7,8-dihydroxy-anti-9,10-epoxy-7,8,9,10-tetrahydrobenzo[a]pyrene). Biochemistry. 2002;41:6100-6.

10. Huang $X$, Kolbanovskiy A, Wu X, Zhang $Y$, Wang Z, Zhuang $P$, et al. Effects of base sequence context on translesion synthesis past a bulky (+)-transanti-B[a]P-N2-dG lesion catalyzed by the Y-family polymerase pol kappa. Biochemistry. 2003;42:2456-66.

11. Avkin S, Goldsmith M, Velasco-Miguel S, Geacintov N, Friedberg EC, Livneh Z. Quantitative analysis of translesion DNA synthesis across a benzo[a]pyrene-guanine adduct in mammalian cells: the role of DNA polymerase kappa. J Biol Chem. 2004;279:53298-305.

12. Zhang Y, Yuan F, Wu X, Wang M, Rechkoblit O, Taylor JS, et al. Error-free and error-prone lesion bypass by human DNA polymerase kappa in vitro. Nucleic Acids Res. 2000;28:4138-46.

13. Haracska L, Prakash L, Prakash S. Role of human DNA polymerase kappa as an extender in translesion synthesis. Proc Natl Acad Sci U S A. 2002;99: 16000-5.

14. Jaloszynski P, Ohashi E, Ohmori H, Nishimura S. Error-prone and inefficient replication across 8-hydroxyguanine (8-oxoguanine) in human and mouse ras gene fragments by DNA polymerase kappa. Genes Cells. 2005;10:543-50.

15. Kamiya H, Kurokawa M. Mutagenic bypass of 8-oxo-7,8-dihydroguanine (8hydroxyguanine) by DNA polymerase kappa in human cells. Chem Res Toxicol. 2012;25:1771-6.

16. Fischhaber PL, Gerlach VL, Feaver WJ, Hatahet Z, Wallace SS, Friedberg EC. Human DNA polymerase kappa bypasses and extends beyond thymine glycols during translesion synthesis in vitro, preferentially incorporating correct nucleotides. J Biol Chem. 2002;277:37604-11.

17. Yoon JH, Bhatia G, Prakash S, Prakash L. Error-free replicative bypass of thymine glycol by the combined action of DNA polymerases kappa and zeta in human cells. Proc Natl Acad Sci U S A. 2010;107:14116-21.

18. Plosky BS, Frank EG, Berry DA, Vennall GP, McDonald JP, Woodgate R. Eukaryotic Y-family polymerases bypass a 3-methyl-2'-deoxyadenosine analog in vitro and methyl methanesulfonate-induced DNA damage in vivo. Nucleic Acids Res. 2008;36:2152-62.

19. Minko IG, Harbut MB, Kozekov ID, Kozekova A, Jakobs PM, Olson SB, et al. Role for DNA polymerase kappa in the processing of N2-N2-guanine interstrand cross-links. J Biol Chem. 2008;283:17075-82.

20. Ho TV, Guainazzi A, Derkunt SB, Enoiu M, Scharer OD. Structure-dependent bypass of DNA interstrand crosslinks by translesion synthesis polymerases. Nucleic Acids Res. 2011;39:7455-64. 
21. Williams HL, Gottesman ME, Gautier J. Replication-independent repair of DNA interstrand crosslinks. Mol Cell. 2012;47:140-7.

22. Stancel JN, McDaniel LD, Velasco S, Richardson J, Guo C, Friedberg EC. Polk mutant mice have a spontaneous mutator phenotype. DNA Repair (Amst). 2009;8:1355-62.

23. O-Wang J, Kawamura K, Tada Y, Ohmori H, Kimura H, Sakiyama S, et al. DNA polymerase kappa, implicated in spontaneous and DNA damage-induced mutagenesis, is overexpressed in lung cancer. Cancer Res. 2001;61:5366-9.

24. Bavoux C, Leopoldino AM, Bergoglio V, O-Wang J, Ogi T, Bieth A, et al. Upregulation of the error-prone DNA polymerase $\mathrm{k}$ promotes pleiotropic genetic alterations and tumorigenesis. Cancer Res. 2005;65:325-30.

25. Sassa A, Suzuki T, Kanemaru Y, Niimi N, Fujimoto H, Katafuchi A, et al. In vivo evidence that phenylalanine 171 acts as a molecular brake for translesion DNA synthesis across benzo[a]pyrene DNA adducts by human DNA polymerase kappa. DNA Repair (Amst). 2014;15:21-8.

26. Kanemaru Y, Suzuki T, Niimi N, Gruz P, Matsumoto K, Adachi N, et al. Catalytic and non-catalytic roles of DNA polymerase kappa in the protection of human cells against genotoxic stresses. Environ Mol Mutagen. 2015;56:650-62.

27. Waters LS, Minesinger BK, Wiltrout ME, D'Souza S, Woodruff RV, Walker GC. Eukaryotic translesion polymerases and their roles and regulation in DNA damage tolerance. Microbiol Mol Biol Rev. 2009:73:134-54.

28. Moldovan GL, Pfander B, Jentsch S. PCNA, the maestro of the replication fork. Cell. 2007;129:665-79.

29. Tomasz M, Palom Y. The mitomycin bioreductive antitumor agents: crosslinking and alkylation of DNA as the molecular basis of their activity. Pharmacol Ther. 1997;76:73-87.

30. Bizanek R, McGuinness BF, Nakanishi K, Tomasz M. Isolation and structure of an intrastrand cross-link adduct of mitomycin C and DNA. Biochemistry. 1992;31:3084-91.

31. Palom Y, Suresh Kumar G, Tang LQ, Paz MM, Musser SM, Rockwell S, et al. Relative toxicities of DNA cross-links and monoadducts: new insights from studies of decarbamoyl mitomycin C and mitomycin C. Chem Res Toxicol. 2002;15:1398-406

32. Takeiri A, Wada NA, Motoyama S, Matsuzaki K, Tateishi H, Matsumoto K, et al. In vivo evidence that DNA polymerase kappa is responsible for errorfree bypass across DNA cross-links induced by mitomycin C. DNA Repair (Amst). 2014;24:113-21.

33. Bose A, Surugihalli C, Pande P, Champeil E, Basu AK. Comparative Error-Free and Error-Prone Translesion Synthesis of N(2)-2'-Deoxyguanosine Adducts Formed by Mitomycin C and Its Metabolite, 2,7-Diaminomitosene, in Human Cells. Chem Res Toxicol. 2016;29:933-9.

34. Suzuki T, Ukai A, Honma M, Adachi N, Nohmi T. Restoration of mismatch repair functions in human cell line Nalm-6, which has high efficiency for gene targeting. PLoS One. 2013;8, e61189.

35. Suzuki T, Gruz P, Honma M, Adachi N, Nohmi T. Sensitivity of human cells expressing low-fidelity or weak-catalytic-activity variants of DNA polymerase zeta to genotoxic stresses. DNA Repair (Amst). 2016:45:34-43.

36. Liber HL, Thilly WG. Mutation assay at the thymidine kinase locus in diploid human lymphoblasts. Mutat Res. 1982;94:467-85.

37. Clements J. The mouse lymphoma assay. Mutat Res. 2000;455:97-110.

38. Takayama S, Tachibana K. Two opposite types of sister chromatid differential staining in BUdR-substituted chromosomes using tetrasodium salt of EDTA. Exp Cell Res. 1980;126:498-501.

39. Honma M, Hayashi M, Sofuni T. Cytotoxic and mutagenic responses to Xrays and chemical mutagens in normal and p53-mutated human lymphoblastoid cells. Mutat Res. 1997;374:89-98.

40. Adachi N, So S, liizumi S, Nomura Y, Murai K, Yamakawa C, et al. The human pre-B cell line Nalm- 6 is highly proficient in gene targeting by homologous recombination. DNA Cell Biol. 2006;25:19-24.

41. Deans AJ, West SC. DNA interstrand crosslink repair and cancer. Nat Rev Cancer. 2011;11:467-80.

42. Knipscheer P, Raschle M, Smogorzewska A, Enoiu M, Ho TV, Scharer OD, et al. The Fanconi anemia pathway promotes replication-dependent DNA interstrand cross-link repair. Science. 2009;326:1698-701.

43. Zhang J, Walter JC. Mechanism and regulation of incisions during DNA interstrand cross-link repair. DNA Repair (Amst). 2014;19:135-42.

44. Marteijn JA, Lans H, Vermeulen W, Hoeijmakers JH. Understanding nucleotide excision repair and its roles in cancer and ageing. Nat Rev Mol Cell Biol. 2014;15:465-81.

45. Roy U, Scharer OD. Involvement of translesion synthesis DNA polymerases in DNA interstrand crosslink repair. DNA Repair (Amst). 2016;44:33-41.
46. Ho TV, Scharer OD. Translesion DNA synthesis polymerases in DNA interstrand crosslink repair. Environ Mol Mutagen. 2010;51:552-66.

47. Furuta T, Ueda T, Aune G, Sarasin A, Kraemer KH, Pommier Y. Transcriptioncoupled nucleotide excision repair as a determinant of cisplatin sensitivity of human cells. Cancer Res. 2002;62:4899-902.

48. Ogi T, Limsirichaikul S, Overmeer RM, Volker M, Takenaka K, Cloney R, et al. Three DNA polymerases, recruited by different mechanisms, carry out NER repair synthesis in human cells. Mol Cell. 2010;37:714-27.

49. Ogi T, Lehmann AR. The Y-family DNA polymerase kappa (pol kappa) functions in mammalian nucleotide-excision repair. Nat Cell Biol. 2006;8:640-2.

\section{Submit your next manuscript to BioMed Central and we will help you at every step:}

- We accept pre-submission inquiries

- Our selector tool helps you to find the most relevant journal

- We provide round the clock customer support

- Convenient online submission

- Thorough peer review

- Inclusion in PubMed and all major indexing services

- Maximum visibility for your research

Submit your manuscript at www.biomedcentral.com/submit
) Biomed Central 